\title{
Kolorektal premalign polipler ile mide premalign lezyonları arasındaki ilişki
}

\section{Relationship between premalignant colorectal polyps and premalignant gastric lesions}

\section{(D) Harun ERDAL ${ }^{1}$, (D) Armağan GÜNAL ${ }^{2}$, (D) Bülent ÇELIK ${ }^{3}$, (D) Yusuf Serdar SAKINN ${ }^{4}$, (D) Cemal Nuri ERÇIN ${ }^{4}$, (D) Ahmet UYGUN ${ }^{4}$, (D) Mustafa GÜLȘEN ${ }^{4}$}

Sağlık Bilimleri Üniversitesi, Gülhane Eğitim ve Araştırma Hastanesi, ${ }^{1}$ Gastroenteroloji Kliniği, Ankara

Sağlık Bilimleri Üniversitesi, Gülhane Tıp Fakültesi, ${ }^{2}$ Tibbi Patoloji Anabilim Dalı, ${ }^{4}$ Gastroenteroloji Bilim Dall, Ankara

Gazi Üniversitesi, Fen Fakültesi, ${ }^{3}$ statistik Bölümü, Ankara

\begin{abstract}
Giriş ve Amaç: Kolorektal premalign lezyonların en önemlisi poliplerdir. Poliplerin histopatolojisi ve boyutlarına göre malignite riski değismektedir Ayrica mide mukozasinda displazi, atrofi, intestinal metaplazi, polip ve Helicobacter pylori gibi faktörler de mide için prekanseröz durumlardır. Çalışmamızın amaci; kolorektal poliplerin yerleşimi, boyutu, sayısı ve patolojisi ile midenin premalign lezyonlan arasındaki ilişkiyi ortaya koymaktır. Gereç ve Yöntem: Çalışmamız Ekim 2016 ile Ekim 2019 tarihleri arasında 18 yaş ve üzeri hastalara aynı gün yapılan özofagogastroduodenoskopi ve kolonoskopi verilerinin değerlendirildiği retrospektif bir çalışmadır. Inflamatuvar barsak hastalığı olan, mide kanseri ve kolorektal kanser tanısı alan, mide biyopsisi alınmayan, barsak temizliği yetersiz olan ve işlemi tamamlayamayan hastalar çalışmaya dahil edilmemiştir. Bulgular: Iki yüz elli yedi hastanın \%58.0'i erkek ve \%80.9'u 50 yaşın üzerindeydi. Kolorektal poliplerin çoğunluğu distal yerleşimliydi (\%59.1). Ileri adenomatöz polip (IAP) sıkllğı $\% 24.9$ olup ileri adenomatöz polip varlı̆̆ ile 50 yas altı ve üzeri hastalar arasında ve cinsiyete göre istatistiksel fark yoktu (p: 0.659 ve p: 0.747). Helicobacter pylori, atrofi, intestinal metaplazi, displazi ve polip gibi midenin premalign lezyonlan ile ileri adenomatöz polip arasında istatistiksel olarak anlamlı bir ilişki gözlenmedi (p: 0.301). Sonuç: Kolorektal poliplerin yeri, sayısı ve ileri adenomatöz polip ile premalign mide lezyonları arasında iliş̧i saptanmamıştır.
\end{abstract}

Anahtar kelimeler: Kolorektal polip, premalign, prekürsör, mide lezyonu

\section{GİRIS}

Kolorektal kanserler erkeklerde üçüncü, kadınlarda ise ikinci en sik kanserdir (1). Herhangi bir risk faktörü olmasa dahi 50-75 yaş aralığındaki bireylere tarama amaçlı kolonoskopi önerilmektedir (2). Premalign lezyonlar zaman içinde farklı aşamalar sonrası maligniteye progresyon gösterebilmektedir (3). Kolorektal premalign lezyonların çıkarılmasının kolorektal kanserden koruduğu gösterilmiştir $(4,5)$. Adenomatöz polipler kolorektal kanserin en önemli premalign lezyonu olup, poliplerin boyutu büyüdükçe polip içindeki villöz yapı oranı, displazi ve nükleer atipinin derecesi de artmakta ve karsinoma insitu veya invaziv malignite gelişim riski de yükselmektedir (6). Ileri (advanced) adenoma 1 cm'den büyük, yüksek
Background and Aims: Polyps are the most important premalignant colorectal lesions. The risk for malignancy with polyps differs with its histopathology and size. Moreover, factors in the gastric mucosa such as dysplasia, atrophy, intestinal metaplasia, polyp, and Helicobacter pylori are precancerous conditions for the stomach. In this study, we studied the relationship between the location, size, number, and pathology of colorectal polyps and premalignant gastric lesions. Material and Methods: This was a retrospective study that analyzed the data of patients of age $\geq 18$ years who underwent esophagogastroduodenoscopy and colonoscopy on the same day between October 2016 and October 2019. Patients with a history of an inflammatory bowel disease, diagnosis of gastric cancer and colorectal cancer, those who did not undergo gastric biopsy, and those in whom sufficient colonic irrigation was not performed and who could not complete the procedure were excluded from the study. Results: Of the 257 patients, 58\% were men and $80.9 \%$ were $>50$ years of age. The location of the majority of colorectal polyps was distal (59.1\%). The incidence of Advanced Adenomatous Polyp was $24.9 \%$, with no statistical difference in the presence of Advanced Adenomatous Polyp between the ages younger and older than 50 years according to their gender ( $p=0.659$ and $p=0.747$ ). No statistically significant relationship was observed between Advanced Adenomatous Polyp and premalignant gastric lesions, such as Helicobacter pylori, atrophy, intestinal metaplasia, dysplasia, and polyp $(p=0.301)$. Conclusions: No relationship was observed among the location, number, and Advanced Adenomatous Polyp rate of colorectal polyps and premalignant gastric lesions.

Key words: Colorectal polyp, premalignant, precursor, gastric lesion

dereceli displazi veya villöz komponent içeren polipler olarak tanımlanmaktadır (7).

Mide mukozasında kronik gastrit, Helicobacter pylori ( $\mathrm{H}$. pylori) enfeksiyonu, atrofi, intestinal metaplazi ve polip gibi lezyonlardan karsinoma gelişebilmektedir $(8,9)$. Bu lezyonların kolorektal polipler ile olan ilişkisi ile ilgili farklı çalışmalar olup sonuçları çelişkilidir (10-14).

Biz bu çalışmada premalign kolorektal poliplerin yerleşimi, boyutu, sayısı ve histopatolojisi ile gastrointestinal kanalın farklı bir organı olan midenin premalign lezyonları arasındaki ilişkinin gösterilmesini amaçladık. 


\section{GEREC ve YÖNTEM}

\section{Çalışmanın Tasarımı}

Gülhane Eğitim ve Araştırma Hastanesi Gastroenteroloji Kliniği Endoskopi Ünitesinde Ekim 2016-Ekim 2019 tarihleri arasında yapılan özofagogastroduodenoskopi (ÖGD) ve kolonoskopi (KS) verilerinin değerlendirildiği geriye dönük bir çalışmadır. Aynı gün ÖGD ve KS yapılan 18 yaş ve üzeri hastaların işlem raporları geriye dönük gözden geçirilmiştir. Inflamatuvar barsak hastalığı olan, mide kanseri ve kolorektal kanser tanisı alan, mide biyopsisi alınmayan, barsak temizliği yetersiz olan ve endoskopik işlemi tamamlayamayan hastalar çalışmaya dahil edilmemiştir. Şartları sağlayan 257 hasta çalışmaya dahil edilmiştir. Etik kurul onayı, SBÜ Gülhane Eğitim ve Araştırma Hastanesi Girişimsel Olmayan Araştırmalar Etik Kurulu'ndan alınmıştır (Etik kurul no: 2019/19/380).

\section{Histopatolojik İnceleme}

Mide biyopsi örneklerinin histopatolojisinin değerlendirilmesinde Sydney sistemi kullanılmıştır (15). Bu sistemde kronik gastritteki inflamasyonun şiddeti, inflamasyonun aktivitesi, intestinal metaplazi, atrofi ve H. pylori kolonizasyonu parametreleri değerlendirilmektedir. Gastrointestinal sistemin premalign lezyonu olan displazinin değerlendirilip derecelendirilmesinde ise Viyana sınıflaması kullanılmıștır (9).

Kolorektal polip histopatolojisi, yeri ve sayısı ile midenin normal mukozasından alınan biyopsi örneklerinde H. pylori, atrofi, intestinal metaplazi, displazi varlığı, varsa mide poliplerinin histopatolojisi, poliplerin yeri ve sayısı, oluşturulan veri takip formuna kaydedildi. Kolorektal poliplerin yerleşimi proksimal kolon, distal kolon ve pankolon olarak sınıflandırıldı. Proksimal kolon, çekum, çıkan kolon, hepatik fleksura ve transvers kolon prosimal kolon olarak adlandırld. Splenik fleksura, inen kolon, sigmoid kolon ve rektum ise distal kolon olarak adlandırıld. Hem proksimal hem de distal kolonda polip var ise pankolon olarak adlandırıldı. Boyutu büyük (>10 mm), villöz yapı veya yüksek dereceli displazi gibi histopatolojik bulguları olan polipler 'ileri adenomatöz polip' (IAP) olarak adlandırıldı.

\section{İstatistiksel Analizler}

Çalışmadan elde edilen verilerin değerlendirilmesi ve tabloların oluşturulması amacıyla SPSS 15 (Statistical Package for Social Sciences) kullanılmıştır. Kategorik değişkenlerin (nitel değişkenler) sunumu için ise frekans ve yüzde değerler kullanılmıştır. Kategorik değişkenlerin değerlendirilmesinde Chi-Square $\left(\mathrm{X}^{2}\right)$ testi ve gerekli olduğu durumlarda Fisher exact test kullanıldı. Bütün istatistiksel analizlerde anlamlılık düzeyi $\mathrm{p}<0.05$ olarak kabul edilmiştir.

\section{BULGULAR}

Bu çalışmada dahil olma kriterlerini karşılayan 257 hastaya ait veriler analiz edildi. Hastaların \%80.9'u 50 yaşın üzerindeydi. Hastaların çoğu erkekti (\%58.0). Kolorektal poliplerin çoğunluğu distal yerleşimliydi (\%59.1). Polip sayısı açısından ise tek polip olan hastaların oranı \%63.8 saptandı. IAP sıklığı ise \%24.9 idi. Premalign mide lezyonları açısından bakıldığında H. pylori \%53.7, atrofi \%12.1, intestinal metaplazi $\% 19.8$, displazi \%1.2 ve mide polibi saptanma oranı ise \%4.3 idi (Tablo 1).

IAP'nin diğer parametrelerle ilişkisine baktığımızda; 50 yaş altı ve üzeri bireyler arasında istatistiksel olarak fark yoktu (p: 0.659). Benzer şekilde cinsiyete göre de fark saptanmadı (p: 0.747). Proksimal yerleşimli poliplere göre distal kolon ve pankolon yerleşimli poliplerde IAP oranı istatistiksel olarak daha yüksekti (p: 0.032). Kolorektal polip sayısı iki ve üzeri olan hastalarda, tek polip olanlara göre IAP arasındaki anlamlı olarak yüksekti (p: 0.003). H. pylori, atrofi, intestinal metaplazi, displazi ve polip gibi midenin premalign lezyonları ile IAP arasında istatistiksel olarak anlamlı bir ilişki gözlenmedi (Tablo 2).

Tablo 1. Kolon polibi hastalarının dağılımı

\begin{tabular}{|c|c|c|c|}
\hline Değişkenler & & $\mathbf{n}$ & (\%) \\
\hline Yaş & $\begin{array}{l}<=50 \\
>50\end{array}$ & $\begin{array}{c}49 \\
208\end{array}$ & $\begin{array}{l}(19.1) \\
(80.9)\end{array}$ \\
\hline Cinsiyet & $\begin{array}{l}\text { Erkek } \\
\text { Kadın }\end{array}$ & $\begin{array}{l}149 \\
108\end{array}$ & $\begin{array}{l}(58.0) \\
(42.0)\end{array}$ \\
\hline H. pylori & $\begin{array}{l}\text { Yok } \\
\text { Var }\end{array}$ & $\begin{array}{l}119 \\
138\end{array}$ & $\begin{array}{l}(46.3) \\
(53.7)\end{array}$ \\
\hline Atrofi & $\begin{array}{l}\text { Yok } \\
\text { Var }\end{array}$ & $\begin{array}{c}226 \\
31\end{array}$ & $\begin{array}{l}(87.9) \\
(12.1)\end{array}$ \\
\hline $\mathrm{IM}$ & $\begin{array}{l}\text { Yok } \\
\text { Var }\end{array}$ & $\begin{array}{c}206 \\
51\end{array}$ & $\begin{array}{l}(80.2) \\
(19.8)\end{array}$ \\
\hline Displazi & $\begin{array}{l}\text { Yok } \\
\text { Var }\end{array}$ & $\begin{array}{c}254 \\
3\end{array}$ & $\begin{array}{c}(98.8) \\
(1.2)\end{array}$ \\
\hline Mide polip & $\begin{array}{l}\text { Yok } \\
\text { Var }\end{array}$ & $\begin{array}{c}246 \\
11\end{array}$ & $\begin{array}{c}(95.7) \\
(4.3)\end{array}$ \\
\hline KP yeri & $\begin{array}{l}\text { Distal } \\
\text { Proksimal } \\
\text { Pan }\end{array}$ & $\begin{array}{c}152 \\
61 \\
44\end{array}$ & $\begin{array}{l}(59.1) \\
(23.7) \\
(17.1)\end{array}$ \\
\hline IAP sinif & $\begin{array}{l}\text { Yok } \\
\text { Var }\end{array}$ & $\begin{array}{c}193 \\
64\end{array}$ & $\begin{array}{l}(75.1) \\
(24.9)\end{array}$ \\
\hline KP sayı & $\begin{array}{l}1 \text { tane } \\
2 \text { tane } \\
3 \text { ve üzeri }\end{array}$ & $\begin{array}{c}164 \\
71 \\
22\end{array}$ & $\begin{array}{l}(63.8) \\
(27.6) \\
(8.6)\end{array}$ \\
\hline
\end{tabular}

H. pylori: Helicobacter pylori; IM: Intestinal metaplazi; KP: Kolon polibi; IAP: lleri adenomatöz polip. 
Tablo 2. IAP ile demografik özellikler ve mide premalign lezyonlanı ilişkisi

\section{İAP sinif}

\begin{tabular}{|c|c|c|c|}
\hline \multirow[t]{2}{*}{ Değişkenler } & & \multicolumn{2}{|c|}{ Yok } \\
\hline & & $\mathbf{n}$ & (\%) \\
\hline \multirow{2}{*}{ Yaş } & $\leq 50$ & 38 & $(77.6)$ \\
\hline & $>50$ & 155 & $(74.5)$ \\
\hline \multirow{2}{*}{ Cinsiyet } & Erkek & 113 & $(75.8)$ \\
\hline & Kadın & 80 & $(74.1)$ \\
\hline \multirow{2}{*}{ H. pylori } & Yok & 91 & $(76.5)$ \\
\hline & Var & 102 & (73.9) \\
\hline \multirow{2}{*}{ Atrofi } & Yok & 168 & $(74.3)$ \\
\hline & Var & 25 & $(80.6)$ \\
\hline \multirow{2}{*}{$\mathrm{IM}$} & Yok & 154 & $(74.8)$ \\
\hline & Var & 39 & $(76.5)$ \\
\hline \multirow{2}{*}{ Displazi } & Yok & 190 & $(74.8)$ \\
\hline & Var & 3 & $(100.0)$ \\
\hline \multirow{2}{*}{ Mide polibi } & Yok & 183 & (74.4) \\
\hline & Var & 10 & (90.9) \\
\hline \multirow{3}{*}{ KP yeri } & Distal & 111 & $(73.0)$ \\
\hline & Proksimal & 53 & (86.9) \\
\hline & Pan & 29 & (65.9) \\
\hline \multirow{2}{*}{ KP sayısı } & 1 tane & 133 & (81.1) \\
\hline & 2 ve üzeri & 60 & $(64.5)$ \\
\hline
\end{tabular}

Var (\%)

$11 \quad(22.4)$

$53 \quad(25.5)$

$36 \quad(24.2)$

$28 \quad(25.9)$

$28 \quad(23.5)$

$36 \quad(26.1)$

$58 \quad(25.7)$

$\begin{array}{cc}58 & (25.7) \\ 6 & (19.4)\end{array}$

$52 \quad$ (25.2)

12 (23.5)

$64 \quad$ (25.2)

(25.6)

(9.1)

(27.0)

(13.1)

(34.1)

(18.9)

(35.5)
P Değeri

0.659

0.747

0.636

0.446

0.800

0.576

0.301

0.032

0.003

IAP: lleri adenomatöz polip; H. pylori: Helicobacter pylori; IM: Intestinal metaplazi; KP: Kolorektal polip.

Tablo 3. Kolorektal polip yeri ile demografik özellikler ve mide premalign lezyonları ilişkisi

\section{KP yeri}

\begin{tabular}{|c|c|c|c|}
\hline \multirow[t]{2}{*}{ Değişkenler } & & \multicolumn{2}{|c|}{ Distal } \\
\hline & & $\mathbf{n}$ & $(\%)$ \\
\hline \multirow{2}{*}{ Yaş } & $\leq 50$ & 34 & $(69.4)$ \\
\hline & $>50$ & 118 & $(56.7)$ \\
\hline \multirow{2}{*}{ Cinsiyet } & Erkek & 83 & $(55.7)$ \\
\hline & Kadın & 69 & (63.9) \\
\hline \multirow{2}{*}{ H. pylori } & Yok & 64 & $(53.8)$ \\
\hline & Var & 88 & $(63.8)$ \\
\hline \multirow{2}{*}{ Atrofi } & Yok & 134 & $(59.3)$ \\
\hline & Var & 18 & $(58.1)$ \\
\hline \multirow{2}{*}{$\mathrm{IM}$} & Yok & 121 & $(58.7)$ \\
\hline & Var & 31 & $(60.8)$ \\
\hline \multirow{2}{*}{ Displazi } & Yok & 149 & $(58.7)$ \\
\hline & Var & 3 & $(100.0)$ \\
\hline \multirow{2}{*}{ Mide polibi } & Yok & 145 & (58.9) \\
\hline & Var & 7 & $(63.6)$ \\
\hline \multirow{2}{*}{ KP sayısı } & 1 tane & 111 & $(67.7)$ \\
\hline & 2 ve üzeri & 41 & $(44.1)$ \\
\hline
\end{tabular}

Proksimal

n (\%)

11 (22.4)

$50 \quad(24.0)$

$30 \quad$ (20.1)

$31 \quad$ (28.7)

$33 \quad$ (27.7)

$28 \quad$ (20.3)

$55 \quad$ (24.3)

$6 \quad$ (19.4)

$52 \quad(25.2)$

9 (17.6)

$61 \quad$ (24.0)

$58 \quad$ (23.6)

3 (27.3)

$9 \quad(9.7)$
$52 \quad$ (31.7)

\section{Pan}

n (\%)

$4 \quad(8.2)$

$40 \quad$ (19.2)

$36 \quad(24.2)$

$8 \quad(7.4)$

22 (18.5)

22 (15.9)

$37 \quad$ (16.4)

7 (22.6)

33 (16.0)

11 (21.6)

$44 \quad$ (17.3)

$43 \quad$ (17.5)

$1 \quad(9.1)$

1 (.6)

$43 \quad(46.2)$
P Değeri

0.139

0.002

0.245

0.636

0.415

H. pylori: Helicobacter pylori; IM: Intestinal metaplazi; KP: Kolorektal polip. 
Tablo 4. Kolorektal polip sayısı ile demografik özellikler ve mide premalign lezyonları ilişkisi

\begin{tabular}{|c|c|c|c|c|c|c|}
\hline \multirow{3}{*}{ Değişkenler } & & \multicolumn{4}{|c|}{ KP sayısı } & \multirow{3}{*}{ P Değeri } \\
\hline & & \multicolumn{2}{|c|}{1 Adet } & \multicolumn{2}{|c|}{2 ve Üzeri } & \\
\hline & & $\mathbf{n}$ & $(\%)$ & $\mathbf{n}$ & $(\%)$ & \\
\hline \multirow{2}{*}{ Yaş } & $\leq 50$ & 40 & $(81.6)$ & 9 & (18.4) & \multirow{2}{*}{0.004} \\
\hline & $>50$ & 124 & (59.6) & 84 & $(40.4)$ & \\
\hline \multirow{2}{*}{ Cinsiyet } & Erkek & 81 & (54.4) & 68 & $(45.6)$ & \multirow{2}{*}{$<0.001$} \\
\hline & Kadın & 83 & $(76.9)$ & 25 & (23.1) & \\
\hline \multirow{2}{*}{ H. pylori } & Yok & 74 & $(62.2)$ & 45 & (37.8) & \multirow{2}{*}{0.614} \\
\hline & Var & 90 & $(65.2)$ & 48 & (34.8) & \\
\hline \multirow{2}{*}{ Atrofi } & Yok & 146 & $(64.6)$ & 80 & (35.4) & \multirow{2}{*}{0.478} \\
\hline & Var & 18 & $(58.1)$ & 13 & $(41.9)$ & \\
\hline \multirow{2}{*}{ IM } & Yok & 132 & $(64.1)$ & 74 & $(35.9)$ & \multirow{2}{*}{0.589} \\
\hline & Var & 32 & $(62.7)$ & 19 & (37.3) & \\
\hline \multirow{2}{*}{ Displazi } & Yok & 161 & $(63.4)$ & 93 & (36.6) & \multirow{2}{*}{0.555} \\
\hline & Var & 3 & $(100.0)$ & & & \\
\hline \multirow{2}{*}{ Mide polibi } & Yok & 156 & $(63.4)$ & 90 & $(36.6)$ & \multirow{2}{*}{0.751} \\
\hline & Var & 8 & $(72.7)$ & 3 & (27.3) & \\
\hline
\end{tabular}

KP: Kolorektal polip; H. pylori: Helicobacter pylori; IM: Intestinal metaplazi.

Distal kolonda yerleşimli polipler, pankolonik ve proksimal yerleşimli poliplere göre hem kadınlarda hem erkeklerde anlamlı derecede daha yüksekti (p: 0.002). Poliplerin sayısı ile poliplerin yeri arasında anlamlı bir ilişki mevcuttu $(\mathrm{p}<0.001)$. Tek polipler genellikle distalde iken, iki ve üzeri sayıda polipler hem distal hem de pankolonik yerleşim göstermekteydi. Fakat kolorektal poliplerin yeri ile premalign mide lezyonları arasında bir ilişki saptanmadı (Tablo 3).

Kolorektal poliplerin sayısı 50 yaşın üzerinde anlamlı derecede yüksek bulundu (p: 0.004). Erkeklerde kadınlara göre polip sayısı istatistiksel olarak anlamlı derecede daha yüksekti $(p<0.001)$. Fakat kolorektal polip sayısı ile premalign mide lezyonları arasında bir ilişki gösterilemedi (Tablo 4).

\section{TARTISMA}

Çalışmamızda kolorektal poliplerin yeri, sayısı ve IAP ile premalign mide lezyonları (H. pylori, intestinal metaplazi, atrofi, displazi ve polip) arasında ilişki yoktu. H. pylori enfeksiyonu olan hastalarda kolorektal adenomatöz poliplerin daha sı olduğu gösterilmiştir (14). Brim ve ark. yaptıkları çalışmada kolorektal polip varlı̆̆ ile H. pylori arasında ilişki saptamışken, sonuçlarımıza benzer olarak polip yeri, sayısı ve histopatolojisi ile H. pylori arasında korelasyon gösterilememiştir (12). Yine benzer şekilde, Sonnenberg ve ark.'nın 156.000 hasta ile yaptığı çalışmada kolorektal polip yeri ile H. pylori arasında ilişki gösterilememiştir (16). Kolorektal polip varlığı ile intestinal metaplazi arasında ilişki gösterilmesine rağmen sonuçlarımıza benzer şekilde polip yeri ve sayısı ile intestinal metaplazi ilişkisi saptanmamıştır. Aynı çalışmada gastrik atrofi ve kolorektal po- lip arasında ilişki de gösterilememiştir (10). Fakat gastrik polipler ile kolorektal adenom, özellikle de advanced adenom ile birlikteliğinin daha sık olduğu gösterilmiştir (13). Çalışmamızda olgu sayısı az olmakla birlikte displazi ve gastrik polip ile kolorektal polip yeri, sayısı ve IAP arasında bir ilişki gösteremedik.

O'Brien ve ark.'nın 1867 hasta ve 3371 polip ile yaptığı National Polyp Study çalışmasında poliplerin \%70.0'i sol kolondan kaynaklanmaktaydı (17). Çalışmamızda da polip yeri açısından distal kolonda yerleşimli polipler, pankolonik ve proksimal yerleşimli poliplere göre hem kadınlarda hem erkeklerde anlamlı derecede yüksekti. Tek polipler genellikle distalde iken, iki ve üzeri sayıda polipler ise genellikle hem distal hem de pankolonik yerleşim göstermekteydi.

Erkeklerde IAP sıklığı kadınlara göre 1.5 kat daha fazladır (18). Çalışmamızda IAP sıklığına baktığımızda yaş ve cinsiyet açısından fark bulamadık. Kolorektal polip sayısı iki ve üzerindeki hastalarda tek polip olan hastalara göre IAP anlamlı derecede daha yüksekti. Yine polip sayısı ile korele olarak distal kolon ve pankolonik poliplerde IAP daha sık idi.

Çalışmamızın bazı kısıtllılıları vardır; hasta sayımızın az olması, çalışmanın retrospektif olması, kontrol grubumuzun olmaması nedeniyle hastalarımızdaki kolorektal polip varlığı ile mide premalign lezyon varlığı arasındaki ilişkiye dair verilerimizin olmamasıdır.

Sonuç olarak; çalısmamızda kolorektal poliplerin yeri, sayısı ve tAP ile premalign mide lezyonlanı arasında ilişki gösterilememiştir.

\footnotetext{
"Tüm yazarlar herhangi bir çıkar çatışması olmadığını kabul ederler."
} 


\section{KAYNAKLAR}

1. Jemal A, Bray F, Center MM, et al. Global cancer statistics. CA Cancer J Clin 2011;61:69-90.

2. Rex DK, Boland CR, Dominitz JA, et al. Colorectal Cancer Screening: Recommendations for Physicians and Patients From the U.S. Multi-Society Task Force on Colorectal Cancer. Gastroenterology 2017;153:307-23.

3. Frank SA. Dynamics of Cancer: Incidence, Inheritance, and Evolution. Princeton (NJ): Princeton University Press; 2007. Chapter 3, Multistage Progression. Available from: http://www.ncbi.nlm.nih.gov/books/ NBK1562

4. Winawer SJ, Zauber AG, Ho MN, et al. Prevention of colorectal cancer by colonoscopic polypectomy. The National Polyp Study Workgroup. N Engl J Med 1993;329:1977-81.

5. Zauber AG, Winawer SJ, O'Brien MJ, et al. Colonoscopic polypectomy and long-term prevention of colorectal-cancer deaths. N Engl J Med 2012;366:687-96.

6. Muto T, Bussey HJR, Morson BC. The evolution of cancer of the colon and rectum. Cancer 1975;36:2251-70.

7. Lieberman DA, Rex DK, Winawer SJ, et al. Guidelines for colonoscopy surveillance after screening and polypectomy. Gastroenterology 2012;143:844-57.

8. Dinis-Ribeiro M, Lopes C, da Costa-Pereira A, Moreira-Dias L. We would welcome guidelines for surveillance of patients with gastric atrophic chronic and intestinal metaplasia! Helicobacter 2008;131:75-6.

9. WHO Classification of Digestive System Tumors 5. Ed. 2019 WHO Classification of Tumor Editorial Board (Fatima Carniero et al.) IARC, Lyon, France. Chapter Tumors of the Stomach Fukayama M, Rugge M, Washington MK. Page: 59-110
10. Unler GK, Gokturk HS, Toprak E, Erinanc OH, Korkmaz H. Does the presence of endometrial polyp predict colorectal polyp? Am J Med Sci 2016;351:129-32

11. Kawahara Y, Kodama M, Mizukami K, et al. Endoscopic gastric mucosal atrophy as a predictor of colorectal polyps: a large scale case-control study. J Clin Biochem Nutr 2019;65:153-9.

12. Brim H, Zahaf M, Laiyemo AO, et al. Gastric Helicobacter pylori infection associates with an increased risk of colorectal polyps in African Americans. BMC Cancer 2014;14:296.

13. Zhang S, Zheng D, Yang Z, et al. Patients with gastric polyps need colonoscopy screening at younger age: A large prospective cross-sectional study in China. J Cancer 2019;10:4623-32.

14. Yang W, Yang X. Association between Helicobacter pylori infection and colorectal adenomatous polyps. Gastroenterol Res Pract 2019;2019:7480620.

15. Dixon MF, Genta RM, Yardley JH, Correa P. Classification and grading of gastritis. The updated Sydney System. International Workshop on the Histopathology of Gastritis, Houston 1994. Am J Surg Pathol 1996;20:1161-81

16. Sonnenberg A, Genta RM. Helicobacter pylori is a risk factor for colonic neoplasms. Am J Gastroenterol 2013;108:208-15.

17. O'brien MJ, Winawer SJ, Zauber AG, et al. Flat adenomas in the National Polyp Study: is there increased risk for high-grade dysplasia initially or during surveillance? Clin Gastroenterol Hepatol 2004;2:905-11.

18. Regula J, Rupinski M, Kraszewska E, et al. Colonoscopy in colorectal-cancer screening for detection of advanced neoplasia. N Engl J Med 2006;355:1863-72. 